\title{
Current Status of Humanities Education in Medical Students
}

\author{
Jinguo Wang \\ Department of Urology \\ The First Hospital of Jilin University \\ Changchun, China \\ wangjinguolily@163.com
}

\author{
Na Wang* (corresponding author) \\ Department of Anesthesiology \\ The First Hospital of Jilin University \\ Changchun, China \\ wangna080613@163.com
}

\begin{abstract}
The purpose of this study is to improve medical humanities education and solve the existing problems. To put forward some countermeasures: construction of teachers and subjects and reform of teaching content and methods. To establish a new medical humanistic education system of combining specialized profession with social practice closely. Medical education can achieve comprehensive, harmonious and sustainable development. The combination of the spirits of science and humanism is the goal and orientation for the development of medical sciences.
\end{abstract}

\section{Keywords-Humanities, Education, Medical students}

\section{INTRODUCTION}

Medical education itself contains the humanities education. The lack of humanistic quality in medical education is a kind of major problem in our medical education system. In the course of medical education, the humanity quality education is the original of the medical education, caused by imperfect medical education on the issues of medical ethics. In the medical mode from the traditional biology to modern biological psychology - social medical model transformation period, higher medical colleges and universities to train medical talents is the key to medical professional education and humanistic education. Recognize the importance of medical students' humanistic education, strengthening the construction of medical students' humanistic education to deepen the reform of the medical education has important practical significance. Therefore, this study of medical students' humanistic education present situation, problems and their causes are analyzed, the current development situation of medical students medical humanities education put forward the theory of thinking and countermeasure, offer reference for further medical research humanities education.

\section{Humanities EducAtion In Medicine}

Medicine as cross subject of natural science and humanities, is both a science and to the progress of science and technology, is a man, need humanities nourish, medical science, medical humanities be good, be short of one cannot.

Under the condition of socialist market economy, hospital and medical staff will be inevitably influenced by seek the principles of market economy [1]. Although the medical front with a large noble medical ethics. Medical skills of medical workers, but there is no denying that a few medical staff's mind there are mercenaries, money, utilitarianism and hedonism, extreme individualism and other decadent ideas, moral unbalance, even the moral behavior is out of control, cause the distortion of the doctor-patient relationship unprecedented. Investigation showed that the establishment of the socialist market economy under the new situation, many doctors for scientific career has weakened the perseverance and the pursuit of spiritual and material benefits for individuals more into consideration. Used to all abuses are exposed in the medical industry, and their values, the principle of "to be a qualitative change, only the immediate interests, lack of lofty ideals and aspirations, show the weak service spirit, lack of professional dedication, selfish, greedy indulgence such despicable behavior, even cause the medical dispute or medical accident. This phenomenon has often happened in teaching hospital medical work, seriously affected the image of medical workers, in conflict with the purpose of the national training high-quality medical talents [2].

\section{A. The current status of humanities education and existing problems}

These phenomena, all without exception shows the lack of medical workers in the aspect of humanistic spirit. The lack of humanistic spirit though has a background in the social various aspects of reasons, but the lack of medical education of the humanities also has its responsibility. Because of medical education itself is a teaching task, scheduling more objective phenomenon, is also the medical humanities quality education have intention to not intentional of neglect. Medical students are the future of medical workers, and their humanistic quality of medical work has a direct and important influence in the future. The growth of the lack of humanities courses to medical students bring about great negative influence, led to the medical students the formation of utilitarianism and pragmatism values. Low current medical students humanities quality is obvious to all, graduate students only keen on all kinds of practical learning of medical knowledge, is full of Chinese and western cultural knowledge books very few takers Lack of infiltrating humanistic spirit of medical students, lower life taste, mental state is not high, many students with strong utility value and the significance of life. At the same time a large degree of popularization of higher medical education and graduate enrollment expansion, utilitarianism and egoism ideas spread, largely reduces the training quality of graduate students, 
restricted the benign development of the medical education, and also caused the social question of the quality of medical students' education. Although many medical colleges opened the "two lessons", public relations, social etiquette, such as courses, professional medical practitioners law and rules on the examination of doctors' practice, medical ethics, medical psychology, and the content of health law is forbid to leopard, but overall there are still many deficiencies, effect is unsatisfactory.

With the development of modern society, entered the era of humanism of medicine, the traditional biomedical model are gradually replaced by social a psychological a biomedical model. Modern medicine is based on the experiment, had close relations with natural science, and its diagnosis and treatment process is increasingly dependent on the development of science and technology. The development of medical science and technology a significant feature are: medical science and the humanities social sciences mutual penetration, integration trend. Medicine is the science of human life and health, is the intersection of natural and social, have deep cultural brand, at the same time the nature of medical attribute will contain the humanities, it is the science of human and ultimately to serve the people, it has to do with people's life, health, happiness, safety, and is closely related to the social civilization and is directly related to the way of life and quality of the whole society. Especially in our country, the pursuit of traditional medicine is the harmony of man and nature, regard people as a whole, the humanities characteristics, the comprehensive analysis of the disease are extremely, so the medicine could not leave the text exist alone, the development of medicine is inseparable from the progress of human society [3].

Therefore, the realization of education to promote social development and the need of man's all-round development, to strengthen and improve medical students' humanistic quality education, improve their humanistic quality, cultivate students to become China's medical and health undertakings of qualified builders and successors, to continue to deepen the reform and development of medical and health undertakings, to promote social progress has great and far-reaching significance.

Medical education in our country for a long time have been emphasizing the progress and development of science and technology, and has made brilliant achievements, but because of the attention to professional knowledge and skills, and then put the cultivation of the professional knowledge and medical skills in the medical education, while ignoring the human sciences and the humanities education to its rightful place in the whole education system [4]. Although in recent years to strengthen medical students' humanistic education made some exploration, but as a result of medical students in the humanities undergraduate education is very weak, did not know on thought to strengthen humanistic education in medical students education importance and the urgency, thus make the absence of humanistic education of medical students is more serious.

\section{B. The meaning and significance of humanities education}

In medical colleges and universities library can't satisfy the needs of the medical students' humanistic books, materials, due to lack of funding and other factors, cultural books purchasing, the lack of specialists in purchasing books of humanities, purchasing purpose, planning is not strong, make the humanities books type is not complete, quantity is not enough, can't meet the needs of the students and teachers. Heavy light of the concept, the tendency of medical shift, make the medical students focus on professional knowledge and skills to master and ignore the humanistic qualities of the form [5].

As a graduate student in medical schools in the future are in the department of health, life, trust with "noble cause, should have high sense of responsibility and mission, should value the history and the excellent cultural tradition of the Chinese nation, and to carry forward the national spirit and patriotism of unyielding spirit, strive to grow into love, love the motherland and love of the Chinese nation the builders and successors of socialism [6]. However, due to the influence of the traditional education model in our country, many medical students understanding of the history of Chinese culture and the lack of due. The lack of the motherland, the people's thoughts and feelings of the infinite love dedicated noble sentiments. To solve this problem the key is not to add courses, increase class, with the tide, constantly changing, but in how to reform the content, the improvement method, make contact with social reality, close to the graduate student life, communication by moral cognition and moral behavior, create the environment, promoting development, don't use a fixed model to evaluate students, to guide the graduate students in continuous progress and on the basis of the original. All in all, moral education is not only the ideological and political moral responsibility, but in all subjects teaching and activities are responsibilities; In the process of teaching should not only attach importance to the role of the formal curriculum, also should attach great importance to the role of informal curriculum namely recessive curriculum exerts, and four schools, society, family and students self the integration of the situation.

Innovation is the soul of a nation's progress, is a country prosperous driving force. Talent with innovation ability is the most valuable wealth of a country and nation. Postgraduate education as the highest level of higher education, in the progress of science and technology and development of national economy occupies an important position. Therefore, innovation is the higher education, especially the core of postgraduate education, how to train graduate students innovative thinking, innovative consciousness and innovative ability is the key to the whole education.

\section{How to improve humanities education in medical college?}

Medical college is not for the purpose of cultivating philosopher, but to teach students to pay attention to rational thinking. To help graduate students to master knowledge of medical law of development, the method of make graduate student, according to the world outlook and methodology of dialectical materialism, continuously research and solve the whole problem in medical practice. Medical schools do not aim at cultivating ethicists, but for the graduate student set up the correct values. To teach graduate students firmly establish respect people, care into consciousness, must have the noble professional ethics, a work of the spirit of perseverance. Medical college is not for the purpose of cultivating 
economists, but for graduate students to master the theory and methods of health economy. To make graduate students learn to use scientific attitude analysis problem of justice and efficiency in medical practice, to make the limited resources of health care service for the greatest number of people, rather than the "random inspection, the prescription" [7]. Psychologist, for the purpose of medical colleges and universities is not to train, but to make graduate students master the methods of psychological analysis and psychological treatment. Medical students consciously prevent psychosomatic disease as their duties. Medical college is not only for the purpose of cultivating social activists, but also for letting graduate students master the methods of social prevention, through the way such as social intervention, health education, improve the people's health. Medical education cultivates medical students' scientific literacy, and to shape the humanistic spirit of medical students. Only pay equal attention to both, to cultivate high quality medical workers.

Curriculum is the center of the school teaching carrier, school curriculum is to cultivate the blueprint of future talent. Each time the education reform, finally must deepen, the implementation of the core issues to the course. Therefore, curriculum reform should be a man. The key of the education teaching reform, the current medical colleges in China should be based on the future development of social and medical leopard requirements to personnel qualities, and follow the inherent law of education, optimize the humanities curriculum structure, establish a reasonable medical students humanities curriculum system, and make it become an important part of the medical students' curriculum system structure [8].

Humanistic education is not only education is given priority to with course teaching factors, at the same time also want to cooperate with the campus environment, educational concept and school spirit contact the subtle influence of edification education and to realize, only the harmonious development of the teaching and the teaching factors, they can form a good humanities education atmosphere. Hidden curriculum teaching is not only an important factor of comprehensive quality education, but also a process of innovative consciousness, to develop the innovative quality and developing innovation ability. Relative to the organized, planned to the implementation of the dominant curriculum and teaching activities, hidden curriculum teaching purpose is mainly implemented by osmosis effect.

\section{CONCLUSION}

Medical students' humanities quality education is more and more attention, and in this field, there have been many research results. But due to the particularity of medical professional have their career and social, so in this paper, the perspective of medical students to explore the problems of the graduate student's humanities education, with a new idea. From the current practice of medical students education experience, to strengthen the construction of medical students' humanistic education appears extremely important and urgent.

\section{REFERENCES}

[1] Gao Huanjiang. The Teaching Modes of Mathematics in Vocational Colleges. Education and Vocation. 2011

[2] Zhu Jianguo, Zhang Yi. 50 Methods to Promote Students' Understanding. 2009

[3] Zhang Guolei, Yang Longbin, Li Xiaoming. Education Psychological Research in Higher Education Teaching. Education and Vocation. 2011

[4] Fang Xiangyang, Jin Yi. Empirical Study on Higher Mathematics Learning in Vocational Colleges. Studies in College Mathematics. 2009

[5] Zhang Shunyan. Ideas about Mathematics Teaching. Journal of Mathematics Education . 2004

[6] Chen Lingping, Lingxiqin. Developing College Students' Service Consciousness to Serve the Development of Local Economy: Based on Colleges in Guangxi [A].

[7] Shuguang Liu, Bo Dong, Yan Sun. The Method and Practice of University Students' Creative Education [A].

[8] Haiyan Zhen. Based on the comparison of Chinese and foreign teaching methods of Higher Mathematics in Higher Vocational Colleges-The concept of the derivative as an example [A] 